\title{
CORRECTION TO
}

\section{'DECOMPOSING LINEAR TRANSFORMATIONS'}

\author{
LU WANG and YIQIANG ZHOU
}

The following changes should be made to [4].

The proof of [4, Lemma 2] has a gap (we thank Professor Zhuang Niu for pointing this out to us), and its validity is not verified. Hence, [4, Theorem 1] and its proof should be revised as follows.

Theorem 1 (Revised). Let $\operatorname{End}\left(V_{D}\right)$ be the ring of linear transformations of a right vector space $V$ over a division ring $D$.

(1) If $|D|>3$, then $\operatorname{End}\left(V_{D}\right)$ satisfies $(P)$.

(2) If $|D|>2$, then $\operatorname{End}\left(V_{D}\right)$ satisfies $(Q)$.

Proof. (1) Use the proof of part 1 of [4, Theorem 1], replacing 'Lemmas 2 and 4(1)' by 'Lemmas 1 and 2 of [3]'.

(2) It is well known that $R:=\operatorname{End}\left(V_{D}\right)$ is a von Neumann regular, right self-injective ring. For $|D| \geq 4, R$ satisfies $(P)$ by (1), so $R$ satisfies $(Q)$ by [4, Proposition 5]. So we can assume that $|D|=3$. Thus, every element of $R$ is the sum of an idempotent and a unit of $R$ by [1, Theorem 3.9], and 2 is a unit of $R$. Hence, by [2, Theorem 11], for any $a \in R, a=u+v$ where $u$ is a unit of $R$ and $v^{2}=1$. This shows that $a-v=a-v^{-1}=u$ is a unit. So $R$ satisfies $(Q)$.

\section{References}

[1] V. P. Camillo, D. Khurana, T. Y. Lam, W. K. Nicholson and Y. Zhou, 'Continuous modules are clean', J. Algebra 304(1) (2006), 94-111.

[2] V. P. Camillo and H. P. Yu, 'Exchange rings, units and idempotents', Comm. Algebra 22(12) (1994), 4737-4749.

[3] H. Chen, 'Decompositions of countable linear transformations', Glasg. Math. J. (2010), 427-433.

[4] L. Wang and Y. Zhou, 'Decomposing linear transformations', Bull. Aust. Math. Soc. 83 (2011), 256-261.

(c) 2011 Australian Mathematical Publishing Association Inc. 0004-9727/2011 \$16.00 
LU WANG, Department of Mathematics and Statistics,

Memorial University of Newfoundland, St. John's, Nfld A1C 5S7, Canada e-mail: lu.wang@mun.ca

YIQIANG ZHOU, Department of Mathematics and Statistics,

Memorial University of Newfoundland, St. John's, Nfld A1C 5S7, Canada e-mail: zhou@mun.ca 